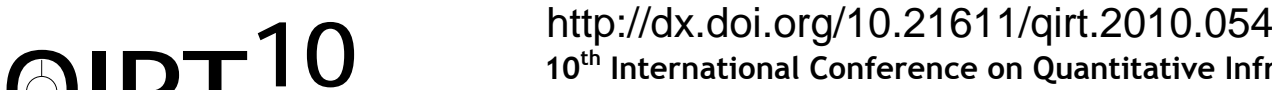 \\ $10^{\text {th }}$ International Conference on Quantitative InfraRed Thermography \\ July 27-30, 2010, Québec (Canada)
}

\section{Effect of nozzle shape on local heat transfer distribution in impinging jets}

\author{
by R. Herrero* and J.M. Buchlin** \\ * von Karman Institute for Fluid Dynamics, Rhode Saint Genèse, Belgium.: ruth.herrero@upct.es \\ ** von Karman Institute for Fluid Dynamics, Rhode Saint Genèse, Belgium.: buchlin@vki.ac.be
}

\begin{abstract}
The paper presents an experimental investigation of heat transfer obtained with impinging gas jets. Lobbed-nozzles are tested. The study parameters are the lob geometry, the jet Reynolds number, Re, and the normalised standoff distance, $\mathrm{Z} / \mathrm{D}_{\mathrm{h}}$. The quantitative infrared thermography associated with the thermofoil technique is applied. At low Reynolds numbers average Nusselt numbers are not too much sensitive to the shape of the nozzle exit. However, at higher Reynolds number ( $>$ 10000) and small standoff distance the effect of nozzle shape affects the local heat transfer distribution. The 3-lob nozzle leads to the best performance.
\end{abstract}

\section{Introduction}

Among heat transfer devices, impinging fluid jets are extensively exploited because of their ability to produce high local transport coefficients. The large heat transfer rate obtained with impinging streams, compared with classical boundary layer flows explains the popularity of this technique. In addition, impingement is often attractive for the designer, who can easily control the area and the distribution of thermal exchange. Impinging jet systems are present in many industrial and engineering processes where heat and/or mass transfer prevail. Typical examples are the annealing of metal and plastic belts, the tempering of glass sheets, the drying of paper and textiles, the cooling of turbine blades, the chemical vapour deposition, propulsion jet- to- flaps interaction in STOL aircraft and thermal anti-icing systems of wings.

The jet can be formed by round (SRN) or slot nozzle (SSN) depending on the application. Reviews on impinging jets have been the subject of numerous works [1-5]. Prior experimental works were carried out by Gardon and Cobonpue [6] who reported the heat transfer distribution for a impinging circular jet for nozzle to plate distances $Z / D_{h}>2$, for a single jet and a array of jets, also Gardon and Akfirat [7] studied the effect of turbulence on the heat transfer for a two dimensional impinging jet. The same authors, in a later work [8], studied the effect of multiple two-dimensional jets on the heat transfer distribution. Later, Hrycak [9] and Baughn and Shimizu and [10] also carried out experimental works to evaluate heat transfer for a round jet using different methods to measure the surface temperature.

At low nozzle-to plate distances, Lytle and Webb [11] investigated the local heat transfer distribution of an impinging circular air jet. Lee et al. [12] analysed the effect of nozzle diameter of an impinging jet on heat transfer and fluid flow. More recently, Beitelmal et al. [13] studied 2D impinging jets and correlated heat transfer at the stagnation point, stagnation region and wall jet region. Hofmann et al. [14] performed an experimental study of the flow structure and heat transfer from a single impinging round jet. In 2007, O'Donovan and Murray [15-16] carried out a very interesting study of the mechanisms that influence the magnitude and location of secondary convective heat transfer peaks.

The effects of nozzle design on heat transfer for impinging air jets has been the subject of several works: Lee and Lee [17] specially emphasized the effect of nozzle edge configurations, Brignoni and Garimella [18] studied the effect of nozzle inlet chamfering on pressure drop and heat transfer characteristics in confined impinging air jet, Lee and Lee [19] conducted an experimental work on the effect of nozzle aspect ratio on the local heat transfer characteristics of elliptic impinging jets, Zhao et al. [20] studied numerically the heat transfer performance of square, elliptic, and rectangular jets. More recently, Zhou and Lee [21] examined the heat transfer and fluid flow characteristics due to impinging air jets from sharp-edged rectangular nozzle of aspect ratio of 4.0. In 2009, Gulati et al [22] studied the influence of the shape of different nozzles on local heat transfer distribution.

Lobed nozzle geometries have also received considerable attention such as the works of Tilman and Presz [23], Power et al [24], Presz et al [25], Hu et al [26], Smith et al [27] Paterson [28] Ukeiley et al [29-30] and Glauser at al [31]. In this perspective, the paper present an experimental study of the thermal convective exchange between incompressible gas jets produced by lobed nozzles and impinging on a heated flat plate. The investigation focuses on the local heat transfer 
distribution obtained for two types of lobs, different jet Reynolds number, Re, and different normalised standoff distances, $\mathrm{Z} / \mathrm{D}_{\mathrm{h}}$.

\section{Experimental Facility}

Figure 1 sketches the experimental test set-up. A jet is produced by blowing air by means of a fan through a settling chamber ending with a converging section followed by a nozzle of long aspect ratio.

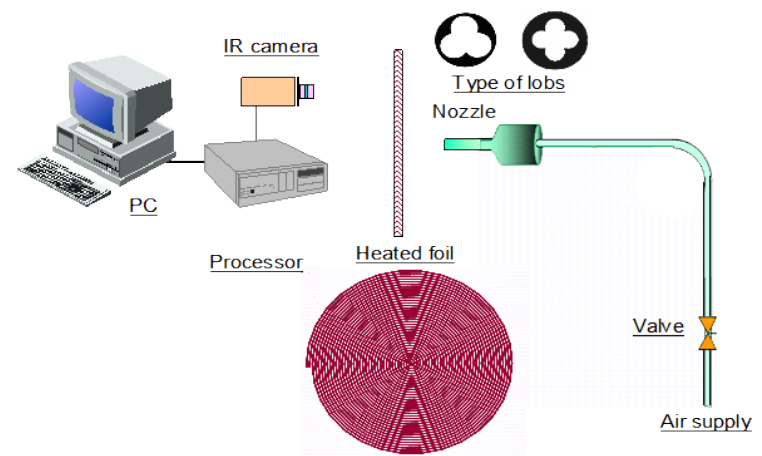

Fig. 1. Schematic of the test set-up

Figure 1 shows also a schematic of the cross-sections of the two lobed nozzles tested and designed with a hydraulic diameter $D_{h}$ of $20 \mathrm{~mm}$. The first nozzle is composed of three lobes (3L); the second nozzle has four lobes (4L).

The jet is oriented perpendicularly to the target, which consists of a flat plate uniformly heated by Joule effect. It is made of a thin copper foil, $40 \mu \mathrm{m}$ thick. The foil is chemically treated to produce a double spiral circuit (see figure 1), $1 \mathrm{~mm}$ wide with grooves of 1 or $2 \mathrm{~mm}$, fixed on an epoxy sheet, less than $1 \mathrm{~mm}$ thick and with diameter of $0.3 \mathrm{~m}$. The resistance circuits are connected to an electrical generator monitored by an ammeter and voltmeter. The infrared radiometer is a Thermocam SC 3000 with an announced NETD of $0.03^{\circ} \mathrm{C}$ at $30^{\circ} \mathrm{C}$. The camera scans the rear face of the foil, which is coated with a black paint of emissivity $\varepsilon_{w}=0.96$ to improve the thermography measurements and allow correction for radiation. The common procedure adopted consists in recording Object Signal (OS) from the IR camera and to apply a VKI in-house DIP software. IR radiometer calibration is performed via thermocouples flush-mounted on the heated foil.

The active method allows the determination of the heat transfer coefficient once the steady state of the thermal exchange between the fluid flow and the heated surface is reached. Then, the convective heat transfer coefficient is inferred from the measured surface temperature $T_{w}(x, y)$ by application of the Newton relation:

$$
h(x, y)=\frac{q_{c v}(x, y)}{T_{w}(x, y)-T_{\text {ref }}}
$$

Since the jet is isothermal with respect to ambient conditions, $T_{\text {ref }}$ is the jet temperature. The convective flux $q_{\mathrm{cv}}$ is obtained by subtracting the heat losses $q_{e}$ to the Joule heating $q_{\mathrm{J}}$. The heat losses include the contribution of the foil conduction $q_{c d}$, the natural convection on the face not exposed to the forced flow and of the radiation $q_{r a d}$. Once the foil properties and the temperature field $\mathrm{T}_{\mathrm{w}}$ are known, $\mathrm{h}$ can be determined. A complete description of this procedure is reported by Buchlin in [32-33].

\section{Results}

Typical thermogrammes are displayed in figure 2. They show qualitatively the effect of the of nozzle shape, Reynolds number Re U. $D_{h} / v$ and normalized standoff distance Z/D . At small Z/D , the 3-lob nozzle produces a triangular thermal footprint while the 4-lob nozzle leads to a square one. However, the effect of the nozzle silhouette disappears progressively as the standoff distance increases. At large standoff distance $\left(Z / D_{h}=12\right)$, no difference in the thermal mapping is found between the lobed and round nozzles.

As expected, the augmentation of Re yields a general drop of the plate temperature as expected but without modifying the general aspect of the thermal footprint. The convective heat transfer data are expressed in terms of the local Nusselt number defined as Nu=h. $D_{h} / k_{a}$, where $k_{a}$ is the thermal conductivity of the air. Figure 3 shows the Nu-profile for normalized standoff distance $\mathrm{Z} / \mathrm{D}_{\mathrm{h}}=0.5$ and Re ranging from 10000 to 50000 . The $3 \mathrm{~L}, 4 \mathrm{~L}$ and round nozzle exits are 
considered; the Nu-profile corresponds to the vertical line passing through the stagnation point. Due to the non-symmetric design of the $3 \mathrm{~L}$ nozzle, both sides, defined by positive and negative values of $r / D_{h}$, are represented.

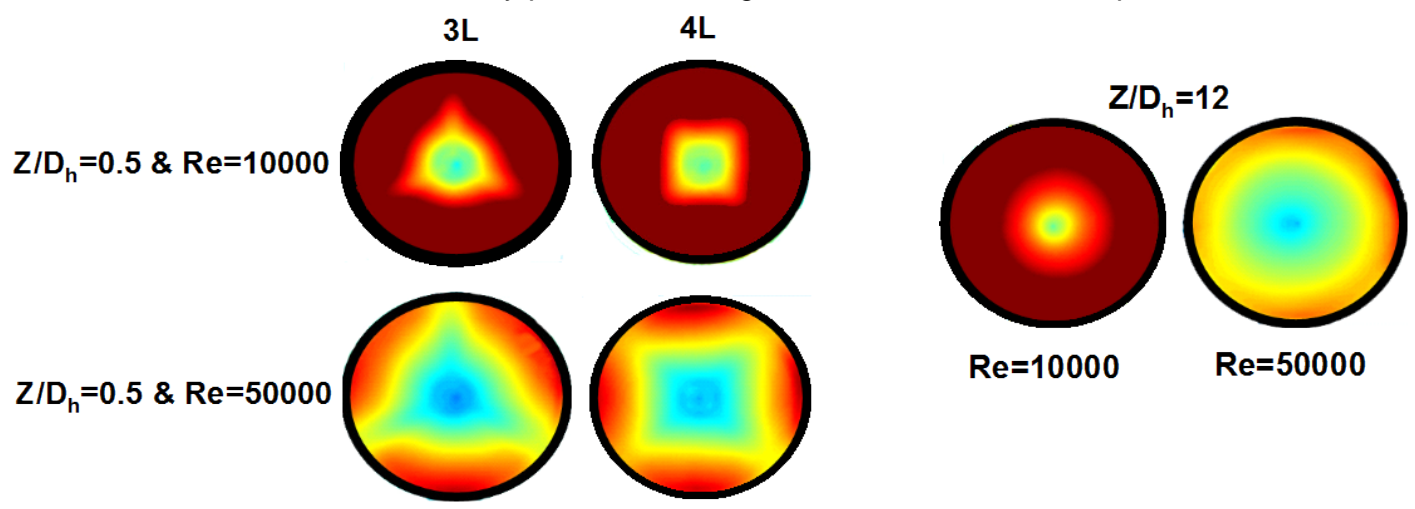

Fig. 2. Typical IR thermogrammes of lobed jet impingement

At the lowest Reynolds number, the round nozzle yields performance slightly better than the lobed nozzles in the stagnation region. As commonly observed at such small standoff distance, the Nu-profile exhibits a drastic change of slope at about $r=D_{h}$, indicating transition of flow regime or presence of vortical structures [32-33]. The dissymmetry of the 3L-nozzle, well marked on the Nu-profile, leads to a higher heat transfer coefficient in the upper wall-jet region compared to the other (right part of figure 3a). However, as Reynolds number increases, the performance of 4L and round nozzle get closer while the $3 \mathrm{~L}$ nozzle provides better heat transfer in a large area around the stagnation point. At high Re-value and despite the very small standoff distance, the $3 \mathrm{~L}$ Nu-profile owns now a regular bell shape without slope accident indicating that the impinging jet behaves surprisingly as a fully developed stream. Same observation is made at $Z / D_{h}=1$ as confirmed by Figure 4 .

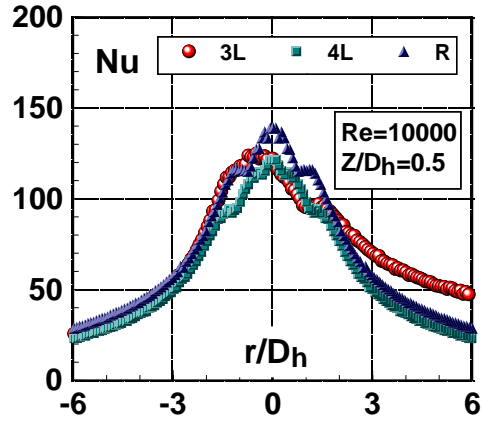

(a)

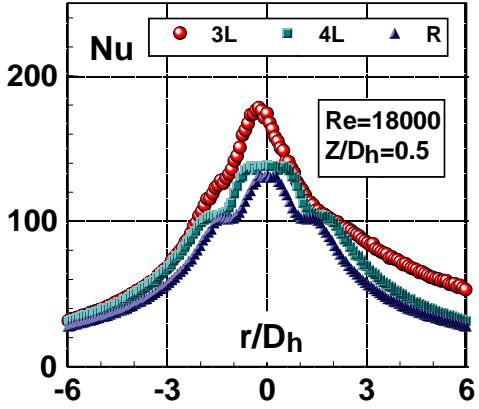

(b)

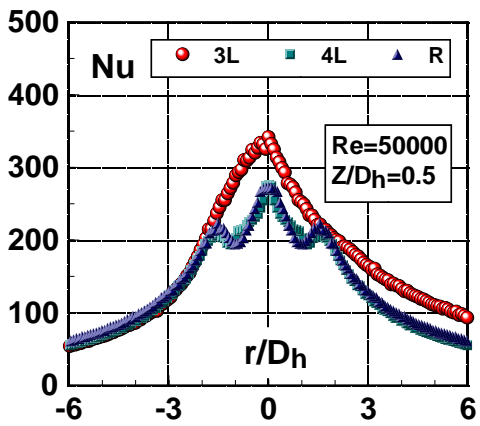

(c)

Fig. 3. Influence of nozzle shape on the local Nusselt number distribution at $Z / D_{h}=0.5$

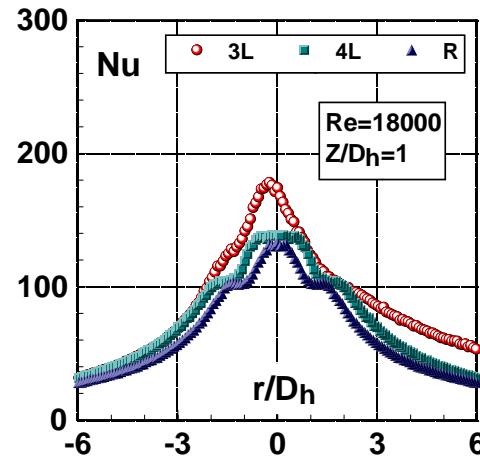

(a)

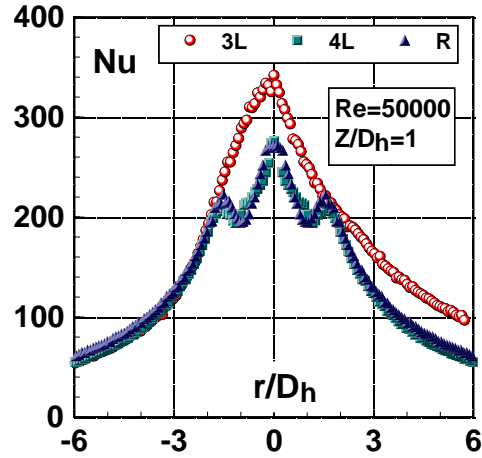

(b)

Fig. 4. Influence of nozzle shape on the local Nusselt number distribution at $Z / D H=1$ 
Figure 5 displays typical results obtained at a higher standoff distance $\left(Z / D_{h}=5\right)$. As the three nozzles move away from the flat plate, all the Nu-profiles tend to merge though the $3 \mathrm{~L}$-nozzle continues to afford performance slightly enhanced particularly in the wall jet region.

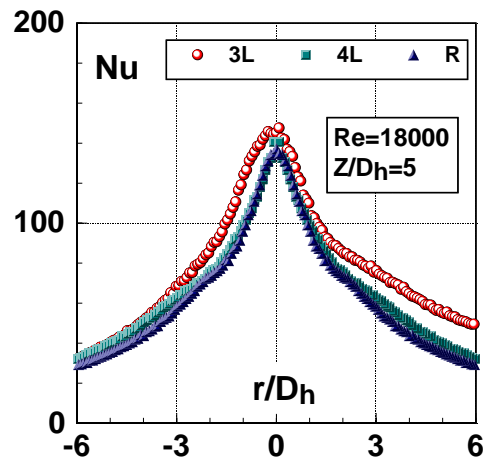

(a)

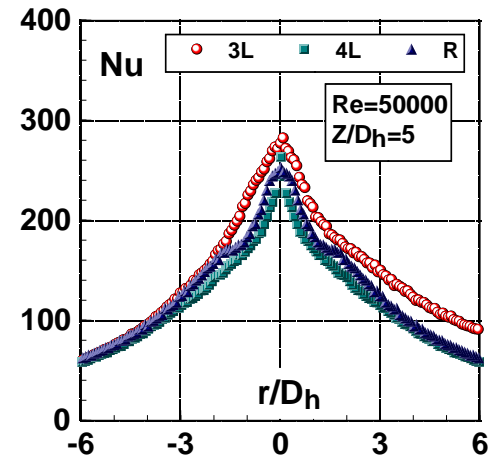

(b)

Fig. 5. Influence of nozzle shape on the local Nusselt number distribution at $\mathrm{Z} / \mathrm{DH}=5$

The evolution of the stagnation Nusselt number, $\mathrm{Nu}_{0}$, with the normalised standoff distance is plotted in figure 6 for two Reynolds numbers. As general trend, $\mathrm{Nu}_{0}$ decreases as $\mathrm{Z} / \mathrm{D}_{\mathrm{h}}$ increases and the three nozzles yield almost the same heat transfer coefficient as the standoff distance exceeds 7 hydraulic diameters. However, figure 6 point out again that the 3Lnozzle performance prevails especially at high Re-value.

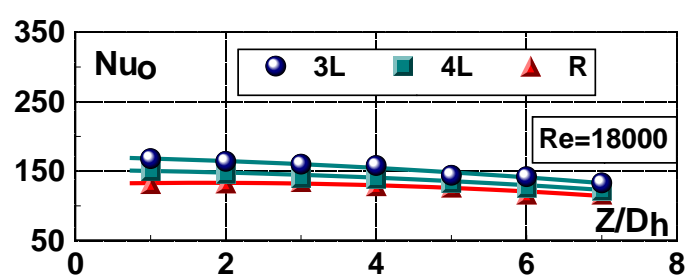

(a)

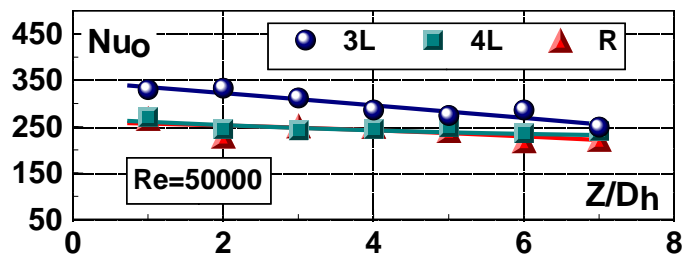

(b)

Fig. 6. Effect of normalised standoff distance on stagnation Nusselt number

\section{Conclusions}

The effect of lobed nozzle on impinging jet heat transfer is experimentally investigated using infrared thermography and active thermofoil technique. The tests are conducted for different Reynolds numbers and different standoff distances.

At low Reynolds number $(\leq 10000)$, local Nusselt number is weakly sensitive to the shape of the nozzle. At high Reynolds number $(\geq 18000)$ ) and small normalised standoff ( $Z / D h \leq 1)$, the 3-lob nozzle affords performance better than 4-lob and round nozzles. However, as the normalised standoff distance increases and exceeds $Z / D_{h}=7$, all the nozzles afford very similar heat transfer data.

\section{REFERENCES}

[1] Livingood, J.N.B. and Hrycak, P. "Impingement heat transfer from turbulent air jets to flat plates - A literature survey", NASA Technical Memorandum (NASA TM X-2778), 1970.

[2] Martin, H., "Heat and mass transfer between impinging gas jets and solid surfaces", Adv. Heat Transfer 13 pp. 1-60, 1977. 
[3] Jambunathan K., Lai E., Moss M. A., Button B. L., "A review of heat transfer data for single circular jet impingement" Int. J. Heat Fluid Flow 13 pp. 106-115, 1992.

[4] Polat, S. "Heat and mass transfer in impingement drying", Drying Technol. 11 pp. 1147-1176, 1993.

[5] Viskanta R., "Heat Transfer to impingement isothermal gas and flame jets", Exp. Therm. Fluid Sci. 6 pp. 111-134, 1993.

[6] Gardon, R. Cobonpue, J. "Heat transfer between a flat plate and jets of air impinging on it, in: Int. Developments in Heat Transfer", ASME, pp. 454-460, 1962.

[7] Gardon, R. Akfirat, C. "The role of turbulence in determining the heat transfer characteristics of impinging jets", International Journal of Heat and Mass Transfer 8, pp. 1261-1272, 1965.

[8] Gardon R., Akfirat, C. "Heat transfer characteristics of impinging two dimensional air jets", Journal of Heat Transfer 88, pp. 101-108, 1966.

[9] Hrycak, P. "Heat transfer from round impinging jets to a flat plate", International Journal of Heat and Mass Transfer 26, pp. 1857-1865,1983.

[10] Baughn, J.W. Shimizu, S. "Heat transfer measurements from a surface with uniform heat flux and an impinging jet", Journal of Heat Transfer 111 pp. 1096-1098, 1989.

[11] Lytle D., Webb B.W., "Air jet impingement heat transfer at low nozzle plate spacing", International Journal of Heat and Mass Transfer 37 pp. 1687-1697, 1994.

[12] Lee, D.H. Song, J. Myeong, C.J. "The effect of nozzle diameter on impinging jet heat transfer and fluid flow", Journal of Heat Transfer 126 pp. 554-557, 2004.

[13] Beitelmal, A.H. Shah, A.J. Saad, M.A. "Analysis of an impinging two dimensional jet", Journal of Heat Transfer 128, pp. 307-310, 2006.

[14] Hofmann, H.M. Kind, M. Martin, H. "Measurements on steady state heat transfer and flow structure and new correlations for heat and mass transfer in submerged impinging jets", International Journal of Heat and Mass Transfer 50 pp. 3957-3965, 2007.

[15] O'Donovan, T.S. Murray D.B., "Jet impingement heat transfer-Part I:Mean and root-mean-square heat transfer and velocity distributions, International Journal of Heat and Mass Transfer 50 pp. 3291-3301, 2007.

[16] O'Donovan T.S., Murray D.B., "Jet impingement heat transfer-Part II: A temporal investigation of heat transfer and local fluid velocities, International Journal of Heat and Mass Transfer 50 pp. 3302-3314, 2007.

[17] Lee, J. Lee S.-J., "The effect of nozzle configuration on stagnation region heat transfer enhancement of axisymmetric jet impingement", International Journal of Heat and Mass Transfer 43 pp. 3497-3509, 2000.

[18] Brignoni, L.A. Garimella, S.V. "Effects of nozzle inlet chamfering on pressure drop and heat transfer in confined air jet impingement", International Journal of Heat and Mass Transfer 43 pp. 1133-1139, 2000.

[19] Lee J., Lee S.-J., "The effect of nozzle aspect ratio on stagnation region heat transfer characteristics of elliptic impinging jet", International Journal of Heat and Mass Transfer 43 pp. 555-575, 2000.

[20] Zhao W., Kumar K., Mujumdar A.S., "Flow and heat transfer characteristics of confined noncircular turbulent impinging jets", Drying Technology 22 pp. 2027-2049, 2004.

[21] Zhou D.W., Lee S.-J., "Forced convective heat transfer with impinging rectangular jets", International Journal of Heat and Mass Transfer 50, pp. 1916-1926, 2007.

[22] Gulati, P. Katti, V. Prabhu S.V. "Influence of the shape of the nozzle on local heat transfer distribution between smooth flat surface and impinging air jet”, International Journal of Thermal Sciences 48 pp. 602-617, 2009.

[23] Tilman T. G. and Presz W. M., Thrust characteristics of a supersonic mixer ejector AIAA 93 (1993) 4345-4352.

[24] Power G D, McClure M D and Vinh D Advanced IR suppresser design using a combined CFD/test approach AIAA (1994) 3215.

[25] Presz W. M., Renyolds G. and McCormick, D. Thrust augmentation using mixer-ejector-diffuser systems AIAA (1994) 0020

[26] $\mathrm{Hu} \mathrm{H}$, Liu H. X. and Wu S.S., Experimental investigation on the aerodynamic performance of the 2D exhaust ejector system ASME 96-GT(1996) 243

[27] Smith L. L., Majamak A. J., Lam I. T., Delabroy O., Karagozian A. R., Marble F. E. and Smith O. I. Mixing enhancement in a lobed injector Phys. Fluids 9 (1997) 667-78

[28] Paterson R.W. Turbofan forced mixer nozzle internal flowfield NASA CR-3492, 1982.

[29] Ukeiley L, Glauser M and Wick D., Downstream evolution of POD eigenfunctions in a lobed mixer AIAA (1993) 4345

[30] Ukeley L., Varghese M, Glauser M and Valentine D., Multifractal analysis of a lobed mixer flowfield utilizing the proper orthogonal decomposition AIAA J 30 (1992)1260-7

[31] Glauser M., Ukeiley L. and Wick D., Investigation of turbulent flows via pseudo flow visualization, part 2: the lobed mixer flow field. Exp. Thermal Fluid Sci. 13 (1996) 167-77.

[32] Buchlin J.-M., Convective Heat Transfer in Impinging-Gas-Jet Systems, in "Aerothermal Performance of Internal Cooling Systems in Turbomachines". von Karman Institute, Lecture Series 2000-03, February 28-March 3, 2000.

[33] Buchlin J.-M., Convective Heat Transfer in Impinging-Gas-Jet Arrangements, 2nd International Conference on Energy Conversion and Conservation, CICME'10, Yesmine - Hammamet - Tunisia,I22-25 April 2010. 